\title{
Strongyloides spp. in cats: a review of the literature and the first report of zoonotic Strongyloides stercoralis in colonic epithelial nodular hyperplasia in cats
}

\author{
Judit M. Wulcan ${ }^{1 *}\left(\mathbb{D}\right.$, Michelle M. Dennis ${ }^{1}$, Jennifer K. Ketzis ${ }^{1}$, Thomas J. Bevelock ${ }^{2}$ and Guilherme G. Verocai ${ }^{2,3}$
}

\begin{abstract}
Background: Four species of Strongyloides, Strongyloides felis, Strongyloides planiceps, Strongyloides stercoralis and Strongyloides tumefaciens, have been identified in cats based on morphology and location in the host with limited data on the prevalence and disease potential of these different species. Strongyloides tumefaciens adults are located in colonic nodules while the other three species are in the small intestine. The literature on Strongyloides in cats is scattered and has never been compiled. The aim of this article is to provide a short review of the existing literature on Strongyloides spp. in cats, to describe the pathology of colonic nodules containing Strongyloides sp. seen at necropsies of cats in St. Kitts, West Indies, and to provide the first unequivocal report of zoonotic S. stercoralis in cats based on sequencing analysis of a portion of the cytochrome c oxidase subunit 1 (cox 1 ) gene, and supported by phylogenetic analysis.
\end{abstract}

Results: Colonic nodules containing sections of nematodes, histologically compatible with Strongyloides sp. were seen during necropsy in six cats in St. Kitts, West Indies. Sequencing of the cox1 gene of the mitochondrial DNA extracted from colonic nodules from two of these cats matched sequences of the zoonotic strain of S. stercoralis.

Conclusions: The morphological similarities between S. stercoralis-associated colonic nodules and previous reports of S. tumefaciens, together with the insufficient defining criteria for $S$. tumefaciens raises questions about the validity of the species. Further sampling and genetic characterization of isolates is needed to understand the species in cats and their zoonotic potential.

Keywords: Colitis, Feline, Strongyloides tumefaciens, Strongyloides felis, Strongyloides planiceps, Pathology, Zoonosis, Strongyloidiasis

\section{Background}

Strongyloides (order Rhabditida, family Strongyloididae) is a genus of nematodes with a complex life-cycle that includes free-living adult stages in the environment and intestinal parasitism with female adults in a wide variety of vertebrates (Fig. 1).

Strongyloides stercoralis is the major Strongyloides species of humans and dogs and has recently been

\footnotetext{
*Correspondence: jmwulcan@gmail.com

${ }^{1}$ Department of Biomedical Sciences, Ross University School of Veterinary

Medicine, PO Box 334, Basseterre, Saint Kitts and Nevis

Full list of author information is available at the end of the article
}

demonstrated to consist of at least two genetically isolated populations, one that is found in dogs and humans and another that has so far exclusively been demonstrated in dogs. The two different populations have not been designated as different species, but are currently referred to as different clades, one that is zoonotic and one that potentially is not $[1,2]$. Prevalence estimates of human infections by S. stercoralis globally ranges from 30 to 100 million people, but many researchers suggest that the true prevalence could be even higher [3].

Hosts of Strongyloides become infected primarily through percutaneous penetration or oral ingestion of 


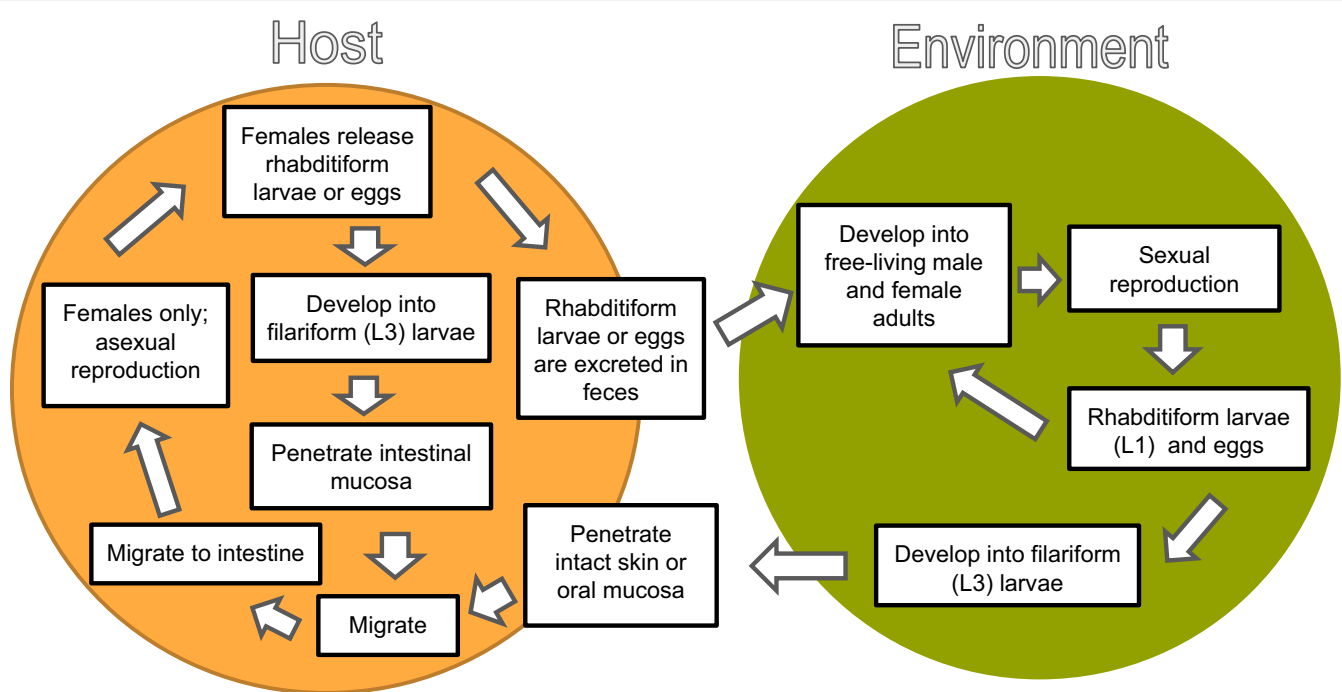

Fig. 1 The complex free-living and parasitic life-cycle of S. stercoralis

infective third-stage larvae (L3). The route of migration to the intestines is not fully understood. A pulmonary route including blood, lungs, trachea and upper gastrointestinal tract is commonly assumed for S. stercoralis; however, experimental infections with dogs indicate that the pulmonary route is not obligate, but rather one of many ways for the larvae to reach the intestines with larvae having limited migration and going more directly to the intestines or migrating through a variety of organs prior to reaching the intestines $[4,5]$. Once in the intestines, infective L3s develop into adult females, which reproduce asexually via parthenogenesis. Eggs or hatched first-stage larvae (L1) are passed in the feces. The L1 can develop into a free-living adult male or female or can develop directly to an infective L3 [6]. Free-living males and females reproduce sexually with the offspring developing again into free-living males and females, depending on the species, or into infective L3 [6]. In addition to the host becoming exposed via infective L3 in the environment, transmammary infection can occur in some species [7]. Also, in humans and dogs, the L1 of $S$. stercoralis produced by the females in the small intestine can develop into infective L3 within the intestines resulting in "autoinfection" $[6,8,9]$.

Most cases of Strongyloides infection in humans and animals, regardless of species, appear to be asymptomatic and self-limiting. When clinical disease is seen, it is usually in the form of acute diarrhea or bronchopneumonia in individuals with high intensity infections [10]. Strongyloides stercoralis infection in immunosuppressed humans and dogs can result in accelerated autoinfection leading to hyperinfection accompanied by exacerbated gastrointestinal and pulmonary signs, sometimes with evidence of disseminated infection. These types of infections are often fatal [11, 12].

Strongyloides spp. in cats is much less studied than Strongyloides in humans or other domestic animals and reports of clinical disease associated with the infection is very rare [13]. The literature on Strongyloides sp. infection in cats is scattered and has never been compiled. Thus, a short review of the condition follows.

Four species of Strongyloides have been reported in cats, namely Strongyloides felis, Strongyloides planiceps, Strongyloides tumefaciens and S. stercoralis. Species identification has been primarily based on morphological features of parasitic adult females, location in the host and eggs (Table 1) with descriptions of the L1 in feces overlapping between the species.

The first of the Strongyloides species described in cats is S. felis by Chandler in 1925 based on specimens from India [14]. Chandler hypothesized that it could be a subspecies of S. stercoralis but that until further data were available, it should be assigned its own species name. There is no further documentation of S. felis until 1986 when it was "rediscovered" from cats in Australia [15, 16]. Since then, there have been no studies specifically focused on the occurrence of S. felis or species validity.

Strongyloides planiceps was first isolated from the flat-headed cat or rusty tiger cat (Prionailurus planiceps) by R. T. Leiper in Malaysia in 1927 and was originally described by Rogers in 1939 [17]. Parasitic female S. planiceps differs from that of S. felis and S. stercoralis in that the ovaries are spiraled versus straight and the tail is bluntly-rounded versus bluntly-pointed (Table 1). Another distinguishing feature mentioned is that the typical fecal stage of S. planiceps is larvated 
Table 1 Brief description of the Strongyloides stages in dogs and cats

\begin{tabular}{|c|c|c|c|c|}
\hline Characteristics & S. stercoralis & S. felis & S. tumefaciens & S.planiceps \\
\hline Location of parasitic female in host & Small intestine & Small intestine & Colonic nodules & Small intestine \\
\hline Length of parasitic female (mm) & $2-3$ & $2.3-3.6$ & $5^{\mathrm{a}}$ & $2.4-3.3$ \\
\hline Ovaries of parasitic female & Straight & Straight & Straight & Spiraled \\
\hline Tail of parasitic female & Bluntly pointed & Bluntly pointed & Bluntly pointed & Bluntly rounded \\
\hline Stage found in feces & Rhabditiform (L1) larvae & Rhabditiform (L1) larvae & Not indicated & Larvated eggs \\
\hline Egg size $(\mu \mathrm{m})$ & $42-58 \times 30-34$ & Similar to S. stercoralis & $114-124 \times 62-68$ & $32-40 \times 58-64$ \\
\hline Length of $\mathrm{L} 1(\mu \mathrm{m})$ & $180-380$ & $217-238$ & 200 & $270-520$ \\
\hline Length of $\mathrm{L} 3(\mu \mathrm{m})$ & $568-662$ & $525-615$ & Not indicated & $490-670$ \\
\hline References & {$[20,54,55]$} & {$[14,15]$} & [24] & {$[17]$} \\
\hline
\end{tabular}

a The length was estimated from pieces of two different worms dissected out from formalin embedded tissue

eggs, whereas S. felis and S. stercoralis primarily shed L1 [17-19]. Sequenced cox 1 of S. planiceps isolated from two Japanese raccoon dogs (Nyctereutes procyonoides) and S. stercoralis isolated from dogs supports that these are different species and indicates that $S$. planiceps and S. stercoralis diverged from a common ancestor prior to separation of dog-parasitic and primate-parasitic clades of $S$. stercoralis [20]. While there are many reports of $S$. planiceps, most are from wild animals and not domestic cats [18]. After the first report of S. planiceps in Malaysia, it has exclusively been reported from Japan where it appears to be most frequently found in raccoon dogs and Japanese weasels (Mustela sibirica) [18, 21, 22].

The life-cycle of S. planiceps and S. felis has been investigated and appears similar to that of S. stercoralis. Adult parthenogenetic females are found in the proximal small intestine and larvated eggs or L1 are passed in the feces $[14,15,17]$. One biological difference between S. planiceps isolated in Japan and S. stercoralis is that multiple generations of free-living adults can be developed experimentally with $S$. planiceps, whereas the eggs from first generation free-living $S$. stercoralis all seem to develop into filariform L3 [23].

Strongyloides tumefaciens was originally described by Price \& Dikmans in a cat from Louisiana, USA, in 1927 and subsequently in a cat from Florida, USA, in 1930 [24]. The species description was based on morphological characteristics of incomplete parasitic females dissected from formalin-fixed paraffin-embedded colonic nodules [24]. As attempts to dissect a complete adult female from the nodules failed, parts from two different worms were pieced together to estimate the length for the adult nematode (approximately $5 \mathrm{~mm}$ ). Apart from the size, morphological features for the parasitic female were similar to those previously described for S. felis and S. stercoralis. A new species, $S$. tumefaciens, was proposed based on the longer size of the adult female and its location in the colon (versus small intestine) [24]. Since then there have been infrequent reports in the USA (1977 and 1987) [25, 26], Brazil (2012 and 2013) [27] and India (1964) [13]. In all cases, female $S$. tumefaciens have only been observed within nodular lesions in the colonic wall; no adults in the lumen or free-living adults have been observed [2427]. The pathology of S. tumefaciens-associated colonic nodules has been similar in all reports from domestic cats [24-27] (Table 2). Multiple 2-20 mm in diameter white submucosal colonic nodules, most apparent from the mucosal surface, that often have a central punctuate depression have been observed in all affected cats. Histologically, the nodules consist of nodular (sometimes referred to as adenomatous) hyperplasia of colonic epithelial cells. The epithelial cells form tubules that extend into the submucosa, are supported by delicate stroma heavily populated by lymphoid cells and contained within a fibrous capsule. Cross-sections of parasitic female nematodes and numerous larvae are abundant throughout the tubules and stroma. In two cases, small numbers of Strongyloides larvae were identified upon fecal examination or within the intestinal lumen $[25,26]$. Clinical data for S. tumefaciens are limited by the fact that the diagnosis has never been made ante mortem.

It is challenging to determine when $S$. stercoralis was first reported in cats. While it had been suggested that $S$. felis could be a subspecies of S. stercoralis [14], attempts to experimentally induce infections in cats with S. stercoralis from dogs and humans resulted in relatively light infections that cleared quickly $[28,29]$. For this reason, S. stercoralis was not considered a normal parasite of cats and the assignment of S. felis as the species of cats remained accepted by many in the field. However, in the last 11 years, there have been reports of $S$. stercoralis in cats from Qatar, Brazil and Kenya [30-32]. These reports do not highlight that S. felis and not S. stercoralis was previously believed to occur in cats and the studies, which 
Table 2 Signalment, history and lesions in cases of S. tumefaciens reported in domestic cats

\begin{tabular}{|c|c|c|c|c|c|}
\hline Location, year & Signalment & History & $\begin{array}{l}\text { Size of colonic } \\
\text { nodules }(\mathrm{mm})\end{array}$ & Other lesions & Reference \\
\hline Louisiana, 1927 & Domestic cat & Died & $2-10$ & ni & {$[24]$} \\
\hline Florida, 1930 & Domestic cat & $\begin{array}{l}\text { Died after period of chronic } \\
\text { diarrhea }\end{array}$ & $2-10$ & ni & {$[24]$} \\
\hline Louisiana, 1977 & $\begin{array}{l}6 \text { months, intact female, Domes- } \\
\text { tic Shorthair (DSH) cat }\end{array}$ & $\begin{array}{l}\text { Died after period of anorexia and } \\
\text { serous oculonasal discharge. } \\
\text { Recent fecal examination with } \\
\text { small numbers of Strongyloides } \\
\text { larvae, A. tubaeforme and T. cati } \\
\text { eggs }\end{array}$ & $2-3$ & Pleuritis & {$[25]$} \\
\hline Georgia, 1987 & Male, Siamese & $\begin{array}{l}\text { Euthanized due to suspicion of } \\
\text { feline leukemia }\end{array}$ & $2-3$ & ni & {$[26]$} \\
\hline Brazil, 2012 & $\begin{array}{l}\text { Adult, male, mongrel domestic } \\
\text { cat }\end{array}$ & $\begin{array}{l}\text { Died after period of debilitation, } \\
\text { muscle weakness and icterus }\end{array}$ & $2-20$ & $\begin{array}{l}\text { Jaundice; focally extensive } \\
\text { necrosuppurative hepatitis; } \\
\text { splenomegaly; lymphadeno- } \\
\text { megaly }\end{array}$ & {$[27]$} \\
\hline Brazil, 2013 & $\begin{array}{l}\text { Adult, male, mongrel domestic } \\
\text { cat }\end{array}$ & $\begin{array}{l}\text { Died after period of chronic diar- } \\
\text { rhea and progressive weight } \\
\text { loss }\end{array}$ & $2-20$ & None & {$[27]$} \\
\hline
\end{tabular}

Abbreviations: ni, not indicated

all lack molecular confirmation of species identification, provide little information regarding how the species was identified.

The true prevalence and geographical distribution of Strongyloides spp. in cats is largely unknown, with most studies reporting the species present based on assumptions regarding the original geographical location of each species. Most cat parasite prevalence studies utilize fecal samples collected at a single time-point and processed using flotation methods, which are known to have a low sensitivity for detecting Strongyloides larvae. The Baermann technique and its modifications were utilized to increase larval detection in only one of the surveys identified in the literature [16]. Prevalence studies, in which Strongyloides spp. have been diagnosed in cats are summarized in Table 3.

\section{Methods}

Literature review

A literature review utilizing the search terms (Strongyloides OR Threadworms) AND (cats OR felines), was performed in PubMed [33] on September 27, 2018. Out of 46 identified records, 17 remained after title and abstract screening. Fourteen additional records were identified

Table 3 Studies in which Strongyloides spp. in cats were demonstrated in some nations

\begin{tabular}{|c|c|c|c|c|c|c|}
\hline Location & $n$ & Prevalence (\%) & Sampling method & Examination method & Species & Reference \\
\hline Australia & 504 & 33.5 & Necropsy & Baermann & S. felis & [16] \\
\hline Australia & 28 & 46.4 & Necropsy & Flotation & Strongyloides sp. & [44] \\
\hline Brazil & 37 & 54.1 & Environmental collection & Flotation & Strongyloides sp. & [39] \\
\hline Brazil & 173 & 13.9 & Environmental collection & Flotation & S. stercoralis ${ }^{\mathrm{a}}$ & {$[31]$} \\
\hline Denmark & 99 & 1.0 & Necropsy & Sedimentation and counting & Strongyloides sp. & [41] \\
\hline England & 131 & 1.5 & ni & Flotation & Strongyloides sp. & {$[40]$} \\
\hline India & ni & 20 & ni & ni & S. felis & [14] \\
\hline Japan & 105 & 3.8 & Necropsy & Flotation & S. planiceps & [22] \\
\hline Kenya & 103 & 43.7 & Litter box collection & Formalin-ether sedimentation & S. stercoralis ${ }^{\mathrm{a}}$ & {$[32]$} \\
\hline Qatar & 824 & 18.4 & Environmental collection & Formalin-ether sedimentation & S. stercoralis ${ }^{\mathrm{a}}$ & [30] \\
\hline Romania & 414 & 3.4 & Litter box collection & Flotation & Strongyloides sp. & [43] \\
\hline Thailand & 300 & 0.7 & ni & Formalin-ether sedimentation & Strongyloides sp. & {$[42]$} \\
\hline
\end{tabular}

a Species identification method unclear

Abbreviations: ni, not indicated 
from review articles, book chapters and unstructured google searches. In total 6 review articles [10, 34-38], 6 experimental studies [19, 21, 23, 28, 29], 13 surveys [14, $16,18,22,30-32,39-44]$ and 6 case reports $[15,17,24-$ 27] were reviewed.

\section{Selection of cases}

Fourteen St. Kitts cats euthanized due to FIV, ill health or accidents between February 2013 and March 2014, underwent necropsy for nematode collection at the Ross University School of Veterinary Medicine, St. Kitts, West Indies. Most of the cats (12/14) were feral cats that had been trapped for spay, neuter and release but were euthanized due to FIV positive status or other health concerns.

Thirty cats, submitted for necropsy from the clinic at the Ross University School of Veterinary Medicine or collected road-killed stray cats, were examined for the presence of colonic nodules between January and July 2018 . These cats were examined with the specific objective to evaluate whether large intestinal nodules were associated with Trichuris sp. infections in cats.

\section{Histopathology}

Grossly visible colonic nodules were collected from all cats. Tissues were fixed in 10\% neutral-buffered formalin, routinely processed and embedded in paraffin wax. Sections cut $4-\mu \mathrm{m}$ thick were stained with hematoxylin and eosin.

\section{Immunohistochemistry}

Colonic sections from four cats with Strongyloides-associated nodules and four cats with colonic nodules consisting of GALT, were evaluated immunohistochemically to detect CD3 (cells of T-cell origin) and CD79a (B-cells).

Immunohistochemistry using polyclonal rabbit antihuman CD3 (DAKO, 1:400) was performed on a Ventana Benchmark XT platform (Ventana Medical Systems Inc., Tucson, AZ, USA) using an anti-rabbit/anti-mouse alkaline phosphatase-labelled polymer detection kit (Ventana Medical Systems Inc., Tucson, AZ, USA) with UltraVIEW Red chromogen and Harris's hematoxylin counterstain (Ventana Medical Systems Inc., Tucson, AZ, USA).

Immunohistochemistry for monoclonal (HM57) mouse anti-human CD79a (DAKO 1:200) was performed on a DAKO autostainer platform (Dako Canada Inc., Burlington, ON, Canada) using a goat anti-mouse horseradish peroxidase-labelled polymer detection kit (UltraVisionONE, Lab Vision Corp., Fremont, CA, USA) with Nova Red chromogen (Vector Laboratories, Burlington, ON, Canada) and Harris's hematoxylin counterstain.

Antigen retrieval was achieved by heat induced epitope retrieval at $\mathrm{pH} 8$ on the Ventana Benchmark XT platform for $\mathrm{CD} 3$, and by heat induced epitope retrieval at $\mathrm{pH} 9$ on a Decloaking Chamber from BioCare Medical (BioCare Medical, Concord, CA, USA) for CD79a.

Negative controls were made by substituting nonimmune rabbit serum (for CD3) or antibody diluent (for CD79a) for the primary antibody. Feline lymph node was used as a positive control.

\section{Molecular analysis}

Extraction of genomic DNA from paraffin-embedded colonic nodules was attempted for 5/6 cats with Strongyloides associated lesions. One cat, with a lesion histologically categorized as a Strongyloides sp. associated colonic nodule was identified after the analysis was performed, and not included. DNA was extracted using a QIAmp DNA FFPE tissue kit following manufacturer's protocol (Qiagen, Valencia, CA, USA).

DNA templates were subjected to a polymerase chain reaction (PCR) for targeting a fragment of the cytochrome $c$ oxidase subunit 1 ( $\operatorname{cox} 1)$ gene of the mitochondrial DNA (mtDNA) using primers TJ5207 (5'-TTT GAT TGT TAC CTG CTT CTA TTT T-3') and TJ5208 (5'-TTT TAC ACC AGT AGG AAC AGC AA-3') [1]. PCR was performed in $25 \mu \mathrm{l}$ reactions including $\mathrm{Go}^{\mathrm{TM}} \mathrm{Taq}$ Green Master Mix (Promega, Madison, WI, USA), 0.5 $\mu \mathrm{mol} / \mathrm{l}$ of each primer and $5 \mu \mathrm{l}$ of DNA template. PCR conditions followed Jaleta et al. [1] and included: denaturation at $94{ }^{\circ} \mathrm{C}$ for $2 \mathrm{~min}$, followed by 35 cycles of 94 ${ }^{\circ} \mathrm{C}$ for $30 \mathrm{~s}, 50{ }^{\circ} \mathrm{C}$ for $15 \mathrm{~s}$, and $72{ }^{\circ} \mathrm{C}$ for $90 \mathrm{~s}$, with a final 10 min extension at $72{ }^{\circ} \mathrm{C}$. Successful amplification was confirmed by visualization of bands of approximately 650 bp using gel electrophoresis. PCR products were purified using the E.Z.N.A. Cycle Pure kit (Omega Bio-Tek, Norcross, GA, USA) and sequenced in both directions using the forward and reserves PCR primers using BigDye Terminator Cycle Sequencing (Applied Biosystems, Foster city, CA, USA).

\section{Phylogenetic analysis}

Fragments of the $\operatorname{cox} 1$ gene from two cats were successfully sequenced, edited and aligned in MEGA v.7 [45]. Phylogenetic analysis was performed using MEGA v.7 [45] using the Maximum Likelihood method with 1000 bootstrap replicates. The best-fitting evolutionary model for the data set was General Time Reversible, Gamma distributed $(G T R+G)$. All sequences were trimmed to $522 \mathrm{bp}$. Homologous sequences of isolates of S. stercoralis from humans, dogs and non-human primates, as well as those of other Strongyloides species, and Necator americanus (outgroup) were included in the analysis.

\section{Total worm counts}

For the cats collected in 2013-2014, the small and large intestine, after sections for histopathology were collected, 
were opened, soaked in saline at approximately $36{ }^{\circ} \mathrm{C}$ for 1 to $3 \mathrm{~h}$ and then scraped and washed over a $50 \mu \mathrm{m}$ sieve. Sieved content was examined for nematodes, with an Olympus SZX16, magnification of $20-100 \times$.

For the cats collected in 2018, the remainder of the whole gastrointestinal tract, divided into stomach, small intestine and large intestine, along with any content was soaked in saline at approximately $36{ }^{\circ} \mathrm{C}$ for $3-24 \mathrm{~h}$ and then scraped and washed over a $100 \mu \mathrm{m}$ sieve. Sieved content was fixed in $5-10 \%$ formalin and stored together with the formalin used for section fixation. The stored small and large intestinal content was examined for nematode stages with an Olympus SZX16 at 25-100× magnification. The person responsible for assessing worm counts was blinded to the intestinal pathology results.

\section{Statistics}

This is a descriptive study. Findings that can be tested statistically (possible associations between number of colonic nodules, size of colonic nodules and CD3/CD79a staining, with Strongyloides infection status) should be investigated in a hypothesis driven study, with appropriate (pre-determined) sample size to avoid spurious results.

\section{Results}

Strongyloides sp. were diagnosed from the postmortem examination of six cats at Ross University School of Veterinary Medicine, St. Kitts, West Indies. For three of these cats, postmortem examinations were performed for collection of specimens of Trichuris sp. between February 2013 and March $2014(n=14)$; and postmortem examinations were performed on the other three cats between January and July 2018, for a study investigating a potential association between large intestinal pathology and Trichuris infection status $(n=30)$. No Strongyloides spp. stages were identified in total worm counts on any of the cats. Grossly, multifocal, slightly raised, off-white nodules, $1-8 \mathrm{~mm}$ in diameter, were observed in the colonic wall of Strongyloides infected cats. The largest nodules were visible from both the mucosal and serosal surfaces, had small pits or depressions on their mucosal surface, and appeared on cut surface to be located in the submucosa (Fig. 2). Microscopically, these nodules consisted of colonic epithelial nodular hyperplasia and colitis containing Strongyloides sp. The nodules were composed of tubules of hyperplastic mucosal epithelial cells, supported by scant fibrous stroma, and containing aggregates of lymphocytes and fewer plasma cells, in some cases mixed with eosinophils, resembling gut associated lymphoid tissue (GALT) (Fig. 3). Strongyloides larvae, adult nematodes, and eggs were within tubules and stroma (Fig. 3). In every case, the diagnosis of Strongyloides sp. was based on morphological features of the parasite in tissue section: adult parasitic females were approximately $110 \mu \mathrm{m}$ in diameter, had platymyarian musculature, an intestine composed of uninucleate cells, and paired genital tracts.

Fragments of the cox 1 gene were successfully sequenced from two samples of two affected cats and were subjected to phylogenetic analysis. In three other affected cats, attempts to extract large enough fragments of DNA for the PCR to work was unsuccessful, most likely due to DNA degradation secondary to FFPE preservation. The two sequences generated belong to S. stercoralis and were identical to each other (GenBank accession numbers: MK463927 and MK463928 [46]), and the pairwise distance between these isolates and other $S$. stercoralis isolates included in the analysis ranged between $0-0.06$. All $S$. stercoralis sequences formed a well-supported clade (99\% bootstrap support). This clade was divided into two well-supported clades. The St. Kitts' cat samples clustered with isolates assumed to be zoonotic and associated to dogs, humans and nonhuman primates from North America, Asia and Africa ( $97 \%$ bootstrap), and the other clade comprised only dog
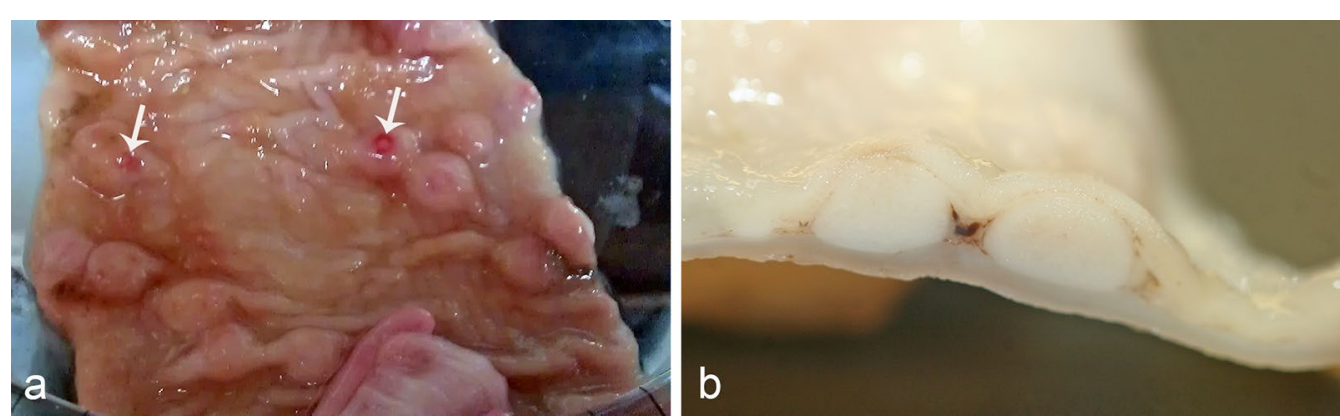

Fig. 2 Strongyloides-associated colonic nodules, cat. a Mucosal surface, colon cat. The nodules are protruding into the mucosal lumen. Small central depressions are visible on the mucosal surface of the nodules (arrows). b Cut surface of colonic nodules 


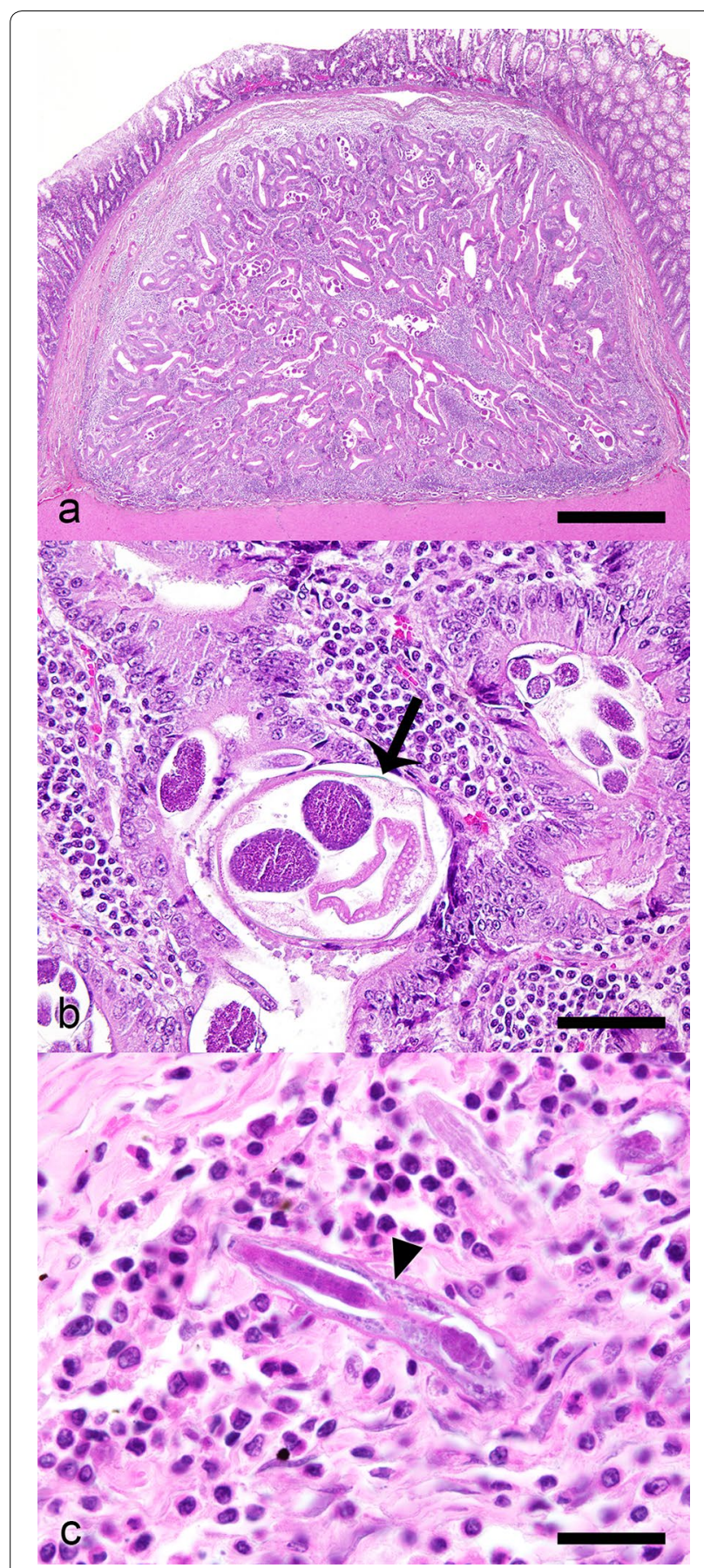

Fig. 3 Strongyloides colonic epithelial nodular hyperplasia, cat. Hematoxylin and eosin. a Encapsulated nodule of hyperplastic colonic epithelial cells which form branching tubules, surrounded by a predominately lymphoplasmacytic infiltrate within the submucosa. b Adult nematodes (arrow) are within tubules. c Rhabditiform larvae (arrowhead) within the nodule stroma surrounded by lymphocytes and plasma cells. Scale-bars: a $250 \mu \mathrm{m}$; b $70 \mu \mathrm{m} ; \mathbf{c} 20 \mu \mathrm{m}$ isolate from East and Southeast Asia (81\% bootstrap) (Fig. 4).

Grossly the Strongyloides sp. associated colonic nodules resembled GALT which was seen in 14 of the 30 cats examined in 2018 and nine of the 14 cats examined in 2013 and 2014. Smaller accumulations of GALT that were not grossly evident were also in the colonic submucosa of all cats.

To evaluate potential distinguishing factors between Strongyloides colonic epithelial nodular hyperplasia and GALT, the size and number, gross appearance, and lymphoid composition of colonic nodules was compared. The number and size of colonic nodules in the 12 cats collected in 2013-2014 was not recorded. For the cats collected in 2018, colonic nodules histologically consisting entirely of GALT were all between 1-2 $\mathrm{mm}$ in diameter, whereas Strongyloides-associated nodules were larger, ranging from $2-8 \mathrm{~mm}$ in diameter (median $4 \mathrm{~mm}$ ). The median number of grossly visible colonic GALT nodules in each cat was 25 (range 5-120), whereas the median number of Strongyloides-associated colonic nodules in each cat was 2 (range 1-15). Mucosal depressions were seen in the Strongyloides-associated nodules (Fig. 5) and the GALT nodules.

The colonic sections submitted for CD3/CD79a (T/B lymphocyte) immunohistochemistry represented four Strongyloides-affected cats, and four non-affected cats, and contained in total 17 Strongyloides-associated nodules and 48 foci of submucosal or mucosal GALT. GALT consistently $(48 / 48)$ was composed of a heterogeneous population of lymphocytes showing cytoplasmic immunoreactivity for CD3 (T-cells) and CD79a (B-cells). All Strongyloides-associated nodules (17/17) consisted predominantly of lymphocytes that stained positive for CD3 (T-cells), and much fewer plasma cells that stained positive for CD79a (B-cells). The sections of Strongyloides stages themselves all stained strongly positive for CD79a (Fig. 6).

\section{Discussion}

The isolation of the zoonotic strain of S. stercoralis from colonic nodules, morphologically similar to lesions previously attributed to $S$. tumefaciens, is the first unequivocal report of S. stercoralis from naturally infected cats. Moreover, it also raises questions regarding the validity of $S$. tumefaciens as a separate species. Morphological differences reported between S. stercoralis, S. tumefaciens and S. felis are limited to morphometric differences determined from only a few observations of often incomplete specimens, specifically in the case of $S$. tumefaciens.

The true diversity of Strongyloides species infecting domestic cats, the true host range, and the validity of some of the species, needs to be reassessed by means of 


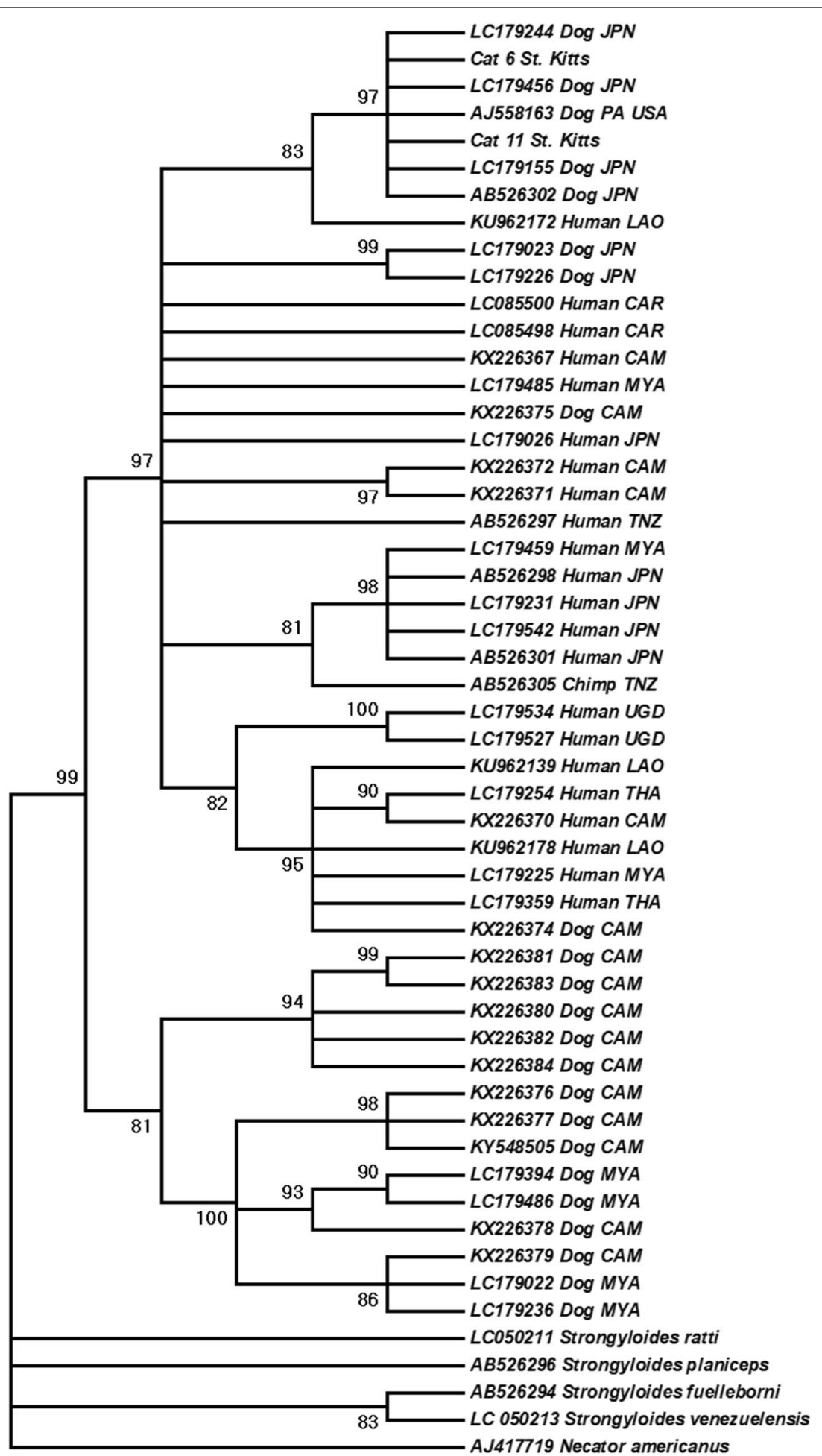

Fig. 4 Maximum likelihood phylogenetic tree depicting the relationship of Strongyloides stercoralis isolates from cats from Saint Kitts ("cat 6 St. Kitts", GenBank accession number MK463927 and "cat 11 St. Kitts", GenBank accession number MK463928), and isolates from different hosts and geographical origins, based on a fragment of the cytochrome c oxidase subunit 1 of the mitochondrial DNA (1000 bootstrap replicates). Numbers at nodes indicate bootstrap values, nodes with less than $80 \%$ support were collapsed 

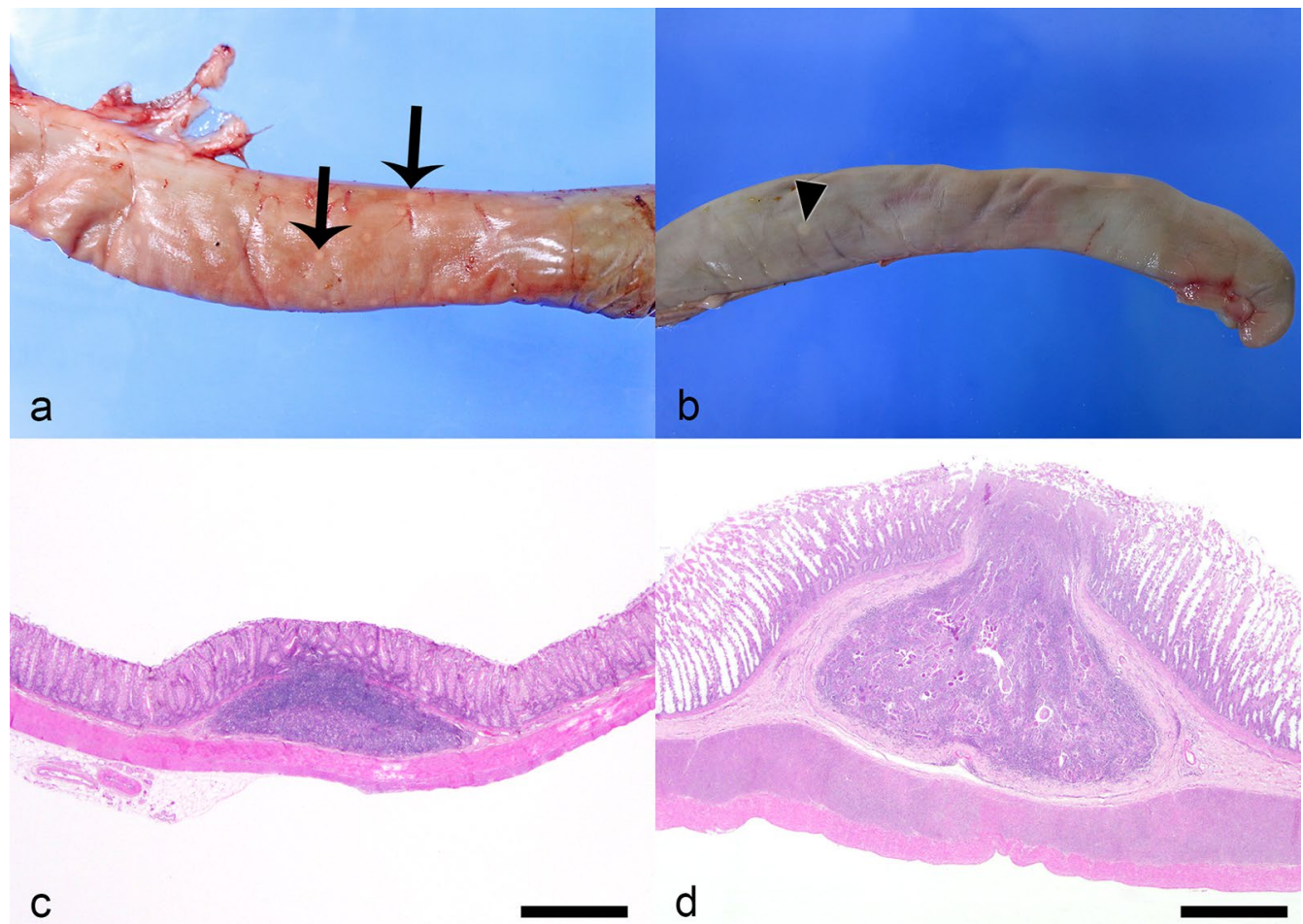

Fig. 5 Comparison of GALT and Strongyloides colonic epithelial nodular hyperplasia, cat. a GALT (arrows) evident from the colonic serosal surface. b A single focus of Strongyloides colonic epithelial nodular hyperplasia (arrowhead) evident from the colonic serosal surface. c Colonic GALT consists of well-demarcated collection of lymphoid tissue within the colonic submucosa. Hematoxylin and eosin. $\mathbf{d}$ Strongyloides colonic epithelial nodular hyperplasia similarly consists of well-demarcated aggregate of lymphocytes and plasma cells, but also contains nematodes and herniated tubules of hyperplastic colonic epithelial cells. Hematoxylin and eosin. Scale-bars: c, d $500 \mu \mathrm{m}$

targeted epidemiological studies using integrated diagnostic approaches which includes the use of the Baermann technique for larval isolation and molecular methods, such as sequencing and phylogenetic analysis. Systematical descriptions of specimens collected in such studies could be used to determine inter- and intraspecies variations in morphological features. To determine potential differences in the life-cycle between different species and hosts, culture of free-living stages and experimental infections of laboratory hosts would be beneficial.

It would be of particular benefit to molecularly characterize nematodes retrieved from cats in the southern USA from where $S$. tumefaciens was originally described and nematodes from cats in Australia, where a high prevalence of $S$. felis has been reported. The pathological presentation of the infection in colonic nodules in cats might provide valuable insight in S. stercoralis pathogenesis. The location of the worms, within colonic nodules, is not typical in most Strongyloides species; however, it is not unheard of in human S. stercoralis infection. In a retrospective case-series from 2011 on 10 human patients with S. stercoralis infections, yellowish-white nodules were observed in the colon. Biopsies of the nodules revealed Strongyloides filariform larvae [47].

The S. stercoralis-associated colonic nodules seen in the study presented herein were not always easy to discern on gross examination from isolated lymphoid nodules, a normal component in the colonic wall. Although all of them were grossly visible, the smaller lesions were less visible from the mucosal surface and were especially similar to GALT. It is therefore likely that these lesions might be more common than they are reported. One possibility is that colonic nodules are a common, but notoriously overlooked feature of $S$. stercoralis infections in general. Another possibility is that it is a reaction to an infection in an unusual, less suitable, host.

The colonic nodules within which the parasites are found have previously been described as primarily epithelial hyperplastic or adenomatous lesions with an inflammatory (predominantly lymphocytic) infiltrate [24-27]. One study suggests the possibility that the lymphoid tissue is remnants of lymphoid clusters (GALT) [27]. GALT includes Peyer's patches in the small intestine and isolated lymphoid follicles throughout the whole gastrointestinal tract. They are part of the afferent or 


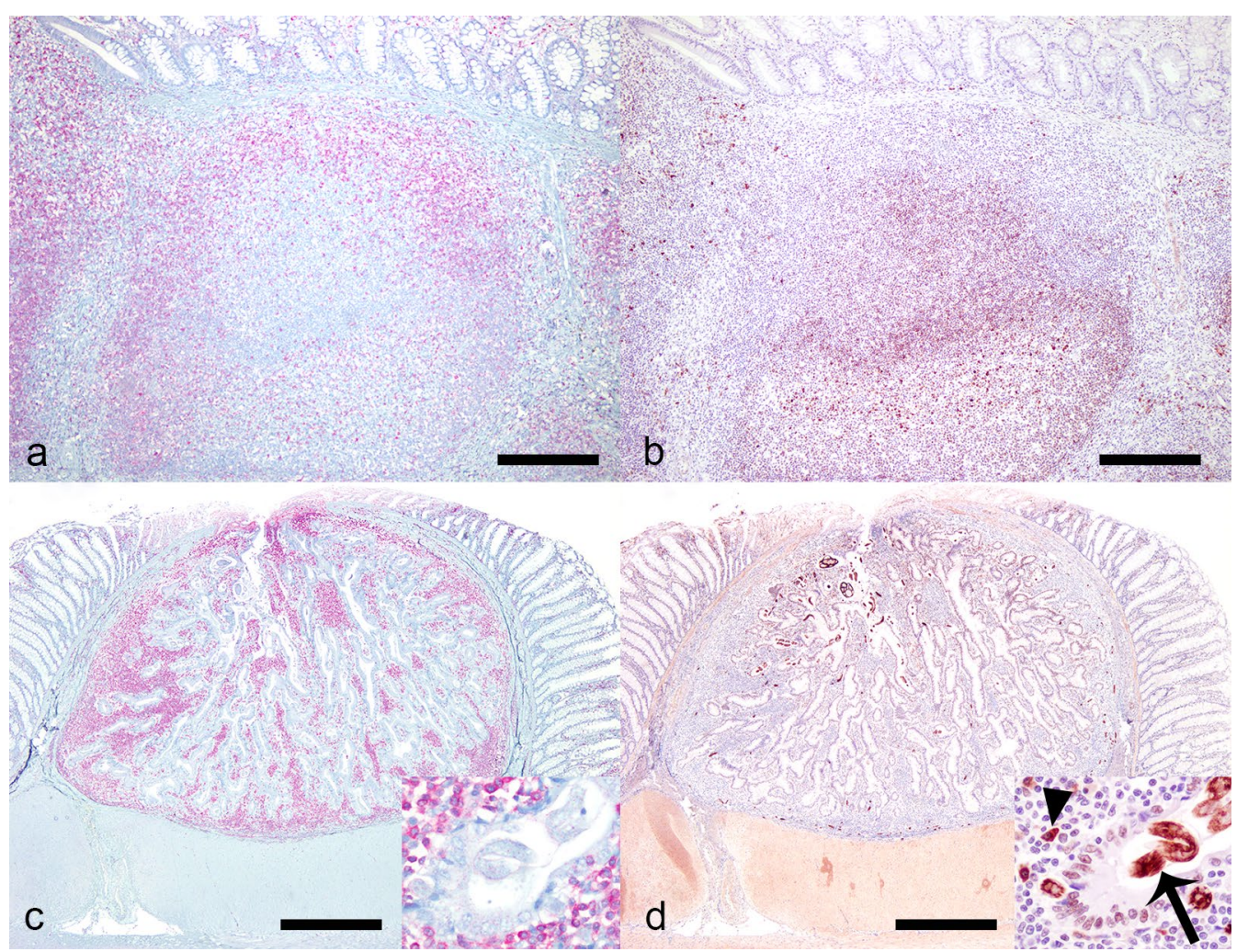

Fig. 6 Comparison of lymphocyte infiltrate in GALT and Strongyloides colonic epithelial nodular hyperplasia, cat. a, b GALT, colon, cat. a There is an unevenly distributed population of T-cells positive for CD3 (Immunohistochemistry for CD3). b There is a similar uneven distribution of B-cells positive for CD79a (Immunohistochemistry for CD79a). c, d Strongyloides colonic epithelial nodular hyperplasia. c The majority are T-cells positive for CD3 (inset) (Immunohistochemistry for CD3). $\mathbf{d}$ Nematodes (inset, arrow) and low numbers of plasma cells (inset arrowhead) are positive for CD79 (Immunohistochemistry for CD79a). Scale-bars: a, b $250 \mu \mathrm{m} ; \mathbf{c}, \mathbf{d} 300 \mu \mathrm{m}$

inductive compartment of the gastrointestinal immune system, which function to prime naive $\mathrm{T}$ and $\mathrm{B}$ cells to initiate the immune response, in response to local antigens. Both Peyer's patches and isolated lymphoid follicles consists of a combination of B-cells and T-cells [48]. All GALT examined in this study consisted of a combination of cells that stained positive for CD3 (T-cells) and cells that stained positive for CD79 (B-cells), whereas the majority of the cells in all Strongyloides-associated nodules examined stained positive with CD3 (T-cells). This may indicate that the Strongyloides-associated nodules are part of an efferent T-cell dominated immune response against the nematodes, rather than herniation into preexisting GALT. Another possibility is that the presence of nematodes within GALT downregulates signals for B-cells which changes the composition of the nodules. This hypothesis is highly speculative as similar mechanisms have not been described previously for Strongyloides spp. There are, however, studies on other parasites where the parasites have been shown to produce proteins that interact with human B-lymphocytes and potentially play a role in suppression of molecules that determine the activation of B-lymphocytes [49]. The strong CD79 staining of intranodular Strongyloides stages observed may be supportive of a similar mechanism for S. stercoralis.

The study reported here from St. Kitts was neither designed to report the prevalence of Strongyloides sp. in cats of St. Kitts nor to evaluate potential risk factors for infection in cats. However, S. stercoralis in St. Kitts' cats is likely not uncommon given the number seen when one specifically looks for them. No Strongyloides stages were, however, observed in any of the total worm counts performed in this study nor have any Strongyloides stages been observed in over 200 fecal flotation analyses performed with feral cats over the last three years. In addition, in a study by Krecek et al. [50] in which several methods were used including Baermann examination, no Strongyloides stages were seen in approximately 100 samples from feral cats from St. Kitts. One explanation could be that fecal excretion is not a common feature of $S$. stercoralis in cats. Alternatively, fecal excretion of eggs and L1 is low and the methods used, or quantity of feces 
analyzed has been insufficient to detect the infections. There are limited data on the prevalence of $S$. stercoralis in humans on St. Kitts, but the prevalence has been estimated to be below 1\% [51]. As with cats, routine fecal analysis for dogs at the RUSVM diagnostic laboratory does not include the Baermann technique and no reports of Strongyloides could be found in recent years with older data not accessible. To further investigate the host range of S. stercoralis encountered in St. Kitts' cats, future prevalence studies could in addition to cats, include humans, dogs and potentially also introduced wildlife, such as wild carnivores (Indian mongoose, Herpestes auropunctatus) and primates (African green monkey, Chlorocebus aethiops sabaeus). In future prevalence studies, the Baermann technique, serial analysis and PCR should be utilized.

On St. Kitts, although there is no feline leukemia virus (FeLV), the prevalence of feline immunodeficiency virus (FIV) is relatively high in the cat population with estimates ranging between $10-30 \%[52,53]$. The frequent observations of Strongyloides in an area high in FIV might be mere coincidence, but as S. stercoralis infection is associated with immunosuppression in humans, a possible association should be evaluated in future studies.

\section{Conclusions}

To our knowledge, this is the first unequivocal report of natural zoonotic $S$. stercoralis infection in cats. The location of S. stercoralis, within colonic nodules consisting of epithelial hyperplasia and cells staining positive for CD3 (T-cells), and the CD79a staining of the intranodular Strongyloides stages observed, may provide new insight to the pathogenesis of this infection. The colonic nodules presented here are morphologically similar to those previously described for S. tumefaciens for which there are insufficient defining criteria, hence raising questions about its validity as a species. Further sampling and genetic characterization of isolates are needed to better define which Strongyloides species infect cats and their zoonotic potential.

\begin{abstract}
Abbreviations
cox1: cytochrome c oxidase subunit 1; FeLV: feline leukemia virus; FIV: feline immunodeficiency virus; GALT: gut associated lymphoid tissue; GSVP: Georgia Veterinary Scholar Summer Programme; L1: first-stage larvae; L3: third-stage larvae; mtDNA: mitochondrial DNA; PCR: polymerase chain reaction.
\end{abstract}

\section{Acknowledgements}

We thank Terje Magnusson and Cyndie Demming for assistance with data collection, Samantha Zayas, Maurice Matthew, Candita Chapman and Randel Thompson for assistance with necropsies, David Hilchie for histological processing, Susan Lapos and the Animal Health Laboratory Histology Team at University of Guelph for immunohistochemical staining, Lewis Bogdanovich for data collection and photographs and The Georgia Veterinary Scholar Summer Programme (GVSP), College of Veterinary Medicine, University of Georgia,
Athens, USA, funded by Boehringer-Ingelheim, for providing stipend support for TJB.

\section{Authors' contributions}

JKK designed and collected the data for the study in 2013-2014. JMW designed and collected the data for the study from 2018. Gross and histopathology from both studies were evaluated by JMW and MMD. Total worm counts from both studies were performed and evaluated by JKK. Molecular and phylogenetic analyses were performed by TJB and GGV. The literature review and the first draft of the paper was prepared by JMW, all authors contributed significantly to the paper. All authors read and approved the final manuscript.

\section{Funding}

This research was funded by the Integrative Mammalian Research center, Ross University School of Veterinary Medicine, St. Kitts, West Indies and Georgia Veterinary Scholar Summer Program (GVSP), College of Veterinary Medicine, University of Georgia, Athens, USA funded by Boehringer-Ingelheim.

\section{Availability of data and materials}

The nucleotide sequences analyzed during the present study are available in the GenBank database under the accession numbers MK463927 and MK463928. Additional datasets used and/or analyzed are available from the corresponding author upon reasonable request.

\section{Ethics approval and consent to participate}

All collection and use of animals were performed under Ross University School of Veterinary Medicine Institutional Animal Care and Use Community approved protocols.

\section{Consent for publication \\ Not applicable.}

\section{Competing interests}

The authors declare that they have no competing interests.

\section{Author details}

${ }^{1}$ Department of Biomedical Sciences, Ross University School of Veterinary Medicine, PO Box 334, Basseterre, Saint Kitts and Nevis. ${ }^{2}$ Department of Infectious Diseases, College of Veterinary Medicine, University of Georgia, 501 D. W. Brooks Drive, Athens, GA 30602, USA. ${ }^{3}$ Department of Veterinary Pathobiology, College of Veterinary Medicine and Biomedical Sciences, Texas A\&M University, College Station, TX 77843, USA.

Received: 1 February 2019 Accepted: 30 June 2019

Published online: 12 July 2019

\section{References}

1. Jaleta TG, Zhou S, Bemm FM, Schär F, Khieu V, Muth S, et al. Different but overlapping populations of Strongyloides stercoralis in dogs and humansdogs as a possible source for zoonotic strongyloidiasis. PLoS Negl Trop Dis. 2017;11:e0005752.

2. Nagayasu E, Aung MPPTHH, Hortiwakul T, Hino A, Tanaka T, Higashiarakawa $M$, et al. A possible origin population of pathogenic intestinal nematodes, Strongyloides stercoralis, unveiled by molecular phylogeny. Sci Rep. 2017;7:4844

3. Bisoffi Z, Buonfrate D, Montresor A, Requena-Méndez A, Muñoz J, Krolewiecki AJ, et al. Strongyloides stercoralis: a plea for action. PLoS Negl Trop Dis. 2013;7:e2214.

4. Schad GA, Aikens LM, Smith G. Strongyloides stercoralis: is there a canonical migratory route through the host? J Parasitol. 1989;75:740-9.

5. Mansfield LS, Alavi A, Wortman JA, Schad GA. Gamma camera scintigraphy for direct visualization of larval migration in Strongyloides stercoralisinfected dogs. Am J Trop Med Hyg. 1995;52:236-40.

6. Viney ME, Lok JB. Strongyloides spp. WormBook, The C. elegans Research community; 2007. https://doi.org/10.1895/wormbook.1.141.1. http:// www.wormbook.org.

7. Shoop WL, Michael BF, Eary CH, Haines HW. Transmammary transmission of Strongyloides stercoralis in dogs. J Parasitol. 2002;88:536-9. 
8. Genta RM, Schad GA, Hellman ME. Strongyloides stercoralis: parasitological, immunological and pathological observations in immunosuppressed dogs. Trans R Soc Trop Med Hyg. 1986;80:34-41.

9. Grove DI, Heenan PJ, Northern C. Persistent and disseminated infections with Strongyloides stercoralis in immunosuppressed dogs. Int J Parasitol. 1983;13:483-90.

10. Thamsborg SM, Ketzis J, Horii Y, Matthews JB. Strongyloides spp. infections of veterinary importance. Parasitology. 2017;144:274-84.

11. Keiser PB, Nutman TB. Strongyloides stercoralis in the immunocompromised population. Clin Microbiol Rev. 2004;17:208-17.

12. Schad GA, Hellman ME, Muncey DW. Strongyloides stercoralis: hyperinfection in immunosuppressed dogs. Exp Parasitol. 1984;57:287-96.

13. Bowman DD, Hendrix CM, Lindsay DS, Barr SC. Feline clinical parasitology. 1st ed. lowa: Iowa State University Press; 2002.

14. Chandler AC. The species of Strongyloides (Nematoda). Parasitology. 1925;17:426-33.

15. Speare R, Tinsley DJ. Strongyloides felis: an "old" worm rediscovered in Australian cats. Aust Vet Pract. 1986;16:10-8.

16. Speare R, Tinsley DJ. Survey of cats for Strongyloides felis. Aust Vet J. 1987;64:191-2

17. Rogers WP. A new species of Strongyloides from the cat. J Helminthol. 1939;17:229-38.

18. Fukase T, Chinone S, Itagaki H. Strongyloides planiceps (Nematoda; Strongyloididae) in some wild carnivores. Nihon Juigaku Zasshi. 1985;47:627-32.

19. Fukase T. Strongyloides planiceps (Nematoda: Strongyloididae) from cats in Kanagawa prefecture, Japan. Nippon Juishikai Zasshi. 1983;36:589-92.

20. Hasegawa H, Sato H, Fujita S, Nguema PPM, Nobusue K, Miyagi K, et al. Molecular identification of the causative agent of human strongyloidiasis acquired in Tanzania: dispersal and diversity of Strongyloides spp. and their hosts. Parasitol Int. 2010;59:407-13.

21. Horie M, Noda S, Noda R. Studies on Strongyloides sp. isolated from a cat and a raccoon dog. Jpn J Parasitol. 1981;30:215-23.

22. Fukase T. Helminthic parasites of stray domestic cats in Kanagawa prefecture, Japan. Nippon Juishikai Zasshi. 1984;37:15-9.

23. Yamada M, Matsuda S, Nakazawa M, Arizono N. Species-specific differences in heterogonic development of serially transferred free-living generations of Strongyloides planiceps and Strongyloides stercoralis. J Parasitol. 1991;77:592-4.

24. Price EW, Dikmans G. Adenomatous tumors in the large intestine of cats caused by Strongyloides tumefaciens n. sp. Proc Helminthol Soc Wash. 1941:8:41-4.

25. Malone JB, Butterfield AB, Williams JC, Stuart BS, Travasos H. Strongyloides tumefaciens in cats. J Am Vet Med Assoc. 1977;171:278-80.

26. Lindsay DS, Blagburn BL, Stuart BB, Gosser HS. Strongyloides tumefaciens infection in a cat. Comp Anim Pract. 1987;1:12-3.

27. Moura MAO, Jorge EM, de Nascimento KKG, Riet-Correa G, Abel I, Cavalcante GG, et al. Colonic epithelial nodular hyperplasia associated with strongyloidiasis in cats in the Amazon region, Pará State, Brazil. Ciência Rural. 2017;47:1-4.

28. Sandground $\mathrm{JH}$. Some studies on susceptibility, resistance, and acquired immunity to infection with Strongyloides stercoralis (Nematoda) in dogs and cats. Am J Epidemiol. 1928;8:507-38.

29. Sandground $\mathrm{JH}$. Speciation and specificity in the nematode genus Strongyloides. J Parasitol. 1925:12:59-80.

30. Abu-Madi MA, Al-Ahbabi DA, Al-Mashhadani MM, Al-Ibrahim R, Pal P, Lewis JW. Patterns of parasitic infections in faecal samples from stray cat populations in Qatar. J Helminthol. 2007;81:281-6.

31. Monteiro MFM, Ramos RAN, Calado AMC, Lima VFS, Ramos ICN, Tenório RFL, et al. Gastrointestinal parasites of cats in Brazil: frequency and zoonotic risk. Rev Bras Parasitol Vet. 2016;25:254-7.

32. Nyambura Njuguna A, Kagira JM, Muturi Karanja S, Ngotho M, Mutharia L, Wangari Maina N. Prevalence of Toxoplasma gondii and other gastrointestinal parasites in domestic cats from households in Thika region, Kenya. Biomed Res Int. 2017;2017:7615810.
33. Pubmeddev Home-PubMed-NCBI. https://www.ncbi.nlm.nih.gov/ pubmed/. Accessed 3 Oct 2018.

34. Hendrix CM, Blagburn BL, Lindsay DS. Whipworms and intestinal threadworms. Vet Clin North Am Small Anim Pract. 1987;17:1355-75.

35. Willard MD, Sugarman B, Walker RD. Gastrointestinal zoonoses. Vet Clin North Am Small Anim Pract. 1987;17:145-78.

36. Genta RM. Strongyloides stercoralis: immunobiological considerations on an unusual worm. Parasitol Today. 1986;2:241-6.

37. Johnson GR. Worms: transmission from animals to man. Am Fam Physician. 1977;15:80-7.

38. Dantas-Torres F, Otranto D. Dogs, cats, parasites, and humans in Brazil: opening the black box. Parasit Vectors. 2014;7:22.

39. Lima VFS, Ramos RAN, Lepold R, Borges JCG, Ferreira CD, Rinaldi L, et al. Gastrointestinal parasites in feral cats and rodents from the Fernando de Noronha Archipelago, Brazil. Rev Bras Parasitol Vet. 2017;26:521-4.

40. Wright I, Stafford K, Coles G. The prevalence of intestinal nematodes in cats and dogs from Lancashire, north-west England. J Small Anim Pract. 2016:57:393-5.

41. Takeuchi-Storm N, Mejer H, Al-Sabi MNS, Olsen CS, Thamsborg SM, Enemark HL. Gastrointestinal parasites of cats in Denmark assessed by necropsy and concentration McMaster technique. Vet Parasitol. 2015;214:327-32.

42. Rojekittikhun W, Chaisiri K, Mahittikorn A, Pubampen S, Sa-Nguankiat S, Kusolsuk T, et al. Gastrointestinal parasites of dogs and cats in a refuge in Nakhon Nayok, Thailand. Southeast Asian J Trop Med Public Health. 2014:45:31-9.

43. Mircean V, Titilincu A, Vasile C. Prevalence of endoparasites in household cat (Felis catus) populations from Transylvania (Romania) and association with risk factors. Vet Parasitol. 2010;171:163-6.

44. Adams PJ, Elliot AD, Algar D, Brazell RI. Gastrointestinal parasites of feral cats from Christmas Island. Aust Vet J. 2008;86:60-3.

45. Kumar S, Stecher G, Tamura K. MEGA7: molecular evolutionary genetics analysis version 7.0 for bigger datasets. Mol Biol Evol. 2016;33:1870-4.

46. Clark K, Karsch-Mizrachi I, Lipman DJ, Ostell J, Sayers EW. GenBank. Nucleic Acids Res. 2016;44:D67-72.

47. Minematsu H, Hokama A, Makishi T, Arakaki K, Kinjo F, Fujita J. Colonoscopic findings and pathologic characteristics of Strongyloides colitis: a case series. Digestion. 2011;83:210-4.

48. Garden OA. Gastrointestinal immunology. In: Washabu RJ, Day MJ, editors. Canine and feline gastroenterology. St. Louis: Saunders; 2013. p. 42-53.

49. Tribolet $L$, Cantacessi $C$, Pickering DA, Navarro S, Doolan DL, Trieu A, et al. Probing of a human proteome microarray with a recombinant pathogen protein reveals a novel mechanism by which hookworms suppress B-cell receptor signaling. J Infect Dis. 2015;211:416-25.

50. Krecek RC, Moura L, Lucas H, Kelly P. Parasites of stray cats (Felis domesticus L, 1758) on St. Kitts, West Indies. Vet Parasitol. 2010;172:147-9.

51. Ketzis JK, Conan A. Estimating occurrence of Strongyloides stercoralis in the Caribbean island countries: implications for monitoring and control. Acta Trop. 2017;171:90-5.

52. Kelly PJ, Stocking R, Gao D, Phillips N, Xu C, Kaltenboeck B, et al. Identification of feline immunodeficiency virus subtype-B on St. Kitts, West Indies by quantitative PCR. J Infect Dev Ctries. 2011:5:480-3.

53. Kelly PJ, Moura L, Miller T, Thurk J, Perreault N, Weil A, et al. Feline immunodeficiency virus, feline leukemia virus and Bartonella species in stray cats on St Kitts, West Indies. J Feline Med Surg. 2010;12:447-50.

54. Grove DI. Human strongyloidiasis. Adv Parasitol. 1996;38:251-309.

55. World Health Organization. Bench aids for the diagnosis of intestinal parasites. Geneva: World Health Organization; 1994.

\section{Publisher's Note}

Springer Nature remains neutral with regard to jurisdictional claims in published maps and institutional affiliations. 